\section{Paired-associate learning predicted from free-association strength: An extension}

\section{S. JOYCE BROTSKY, San Fernando Valley State College, Northridge, Calif. 91324, and MARIGOLD L. LINTON, San Diego State College, San Diego, Calif. 92115}

Forty-eight Ss studied a list of paired associates composed of 60 stimulus words The tendency to give RIs in the test was a function of the preexperimental free-association strength (FAS) between $R I$ and its eliciting stimulus, with significantly more $R 1$ siven to stimuli in the high-FAS group than in the low-FAS group. The amount of facilitation produced by training were given one 4-sec training trial produced fewer R Is in the test than Ss who were given two 4-sec training trials or one 8-sec training trial. Ss who were given $4 \mathrm{sec}$ to respond in the test gave fewer RIs than Ss who were given $8 \mathrm{sec}$ to respond, regardless of training level.

A recent study (Brotsky \& Linton, 1969) examined the relationship between indices of free-association strength (FAS) and paired-associate learning (PAL) with a three-phase procec-ae: (1) a word-association test (WAT) to the stimulus words used in the subsequent PAL task, (2) the paired presentation of the stimulus words and their primary associates (R1) for one or two trials, and ( 3 ) a test of recall of the $\mathrm{R} 1 \mathrm{~s}$. The results indicated that training substantially increased the probability of occurrence of R1 in the test to its eliciting stimulus, and that amount of facilitation varied inversely with the initial FAS of R1. Although the high-FAS R1s were given significantly more frequently than the low-FAS R1s in the test, the amount of facilitation was greater for the low-FAS R1s than for the high-FAS RIs.

Since a great amount of facilitation was produced by training, the probability of giving the R1 to many of the stimuli approached the ceiling of 1.00 in the test. Although a comparison was made between the number of R1s in the test following a single training trial and following two training trials, the results could not be interpreted, since $S s$ in the one-trial group had given more R1s in the WAT than Ss in the two-trial group. Further research seemed necessary to determine the effect of stimulus exposure time and number of training trials in facilitating $R 1$ responding in the test. and their primary normative responses $(R I)$. varied inversely with initial FAS. Ss who
The WAT had been utilized prior to training in the original studies in order to get a direct and, thus, more precise index of FAS than could be obtained from free-association norms. Since the WAT did not prove superior to normative data in predicting PAL, the inclusion of the WAT seemed an unnecessary and, perhaps, contaminating feature of the earlier studies.

The present research was designed to determine if the predicted relationship between FAS and PAL would obtain if the WAT were omitted from the procedure. If the relationship between FAS and PAL is mediated by Ss' response sets, as was hypothesized by the authors (Brotsky \& Linton, 1969), it seemed important to determine if the response set would be activated by the paired presentation of the stimulus-response pairs (S-R1) during training without the prior presentation of a WAT.

An additional concern of the experiment was to determine if Thorndike-Lorge language frequency (Thorndike \& Lorge, 1944) interacted with FAS in the prediction of PAL. Postman (1962) and Martin (1964) have already demonstrated that PAL can be predicted from FAS when the language frequency (TLF) of the stimulus words is low. However, the present study provided the opportunity to determine if PAL varied as a function of FAS with high-TLF stimulus words.

\section{STIMULUS MATERIAL}

Two lists were constructed from the 60 stimulus words used in an earlier study
(Brotsky \& Linton, 1969). The Rls were those responses given most frequently to each of the 60 words in the San Fernando Drum Norms (Brotsky \& Linton, 1968). Three groups of 20 words each [strong FAS, moderate (mod) FAS, and weak FAS] were developed on the basis of the normative frequency of $R 1$ in the drum norms. The 60 words and their Rls are presented in Table 1. Two randomizations of the list were developed (List 1 and List 2).

\section{SUBJECTS}

The Ss were 24 male and 24 female undergraduates from San Diego State College who participated as part of a course requirement. All Ss had been born in the continental United States and had learned English as their first language.

\section{PROCEDURE}

The experiment consisted of two phases: training and test. Training consisted of one or two trials wherein $S$ was asked to study, as pairs, the 60 words and their $R 1 s$, reading the response member aloud as it appeared in the window of a Stowe memory drum. The test consisted of the successive presentation of the 60 words. The $S$ was instructed to give $R 1$ as quickly as possible and to guess if he was not sure of the response. The instructions are reported in detail elsewhere (Brotsky \& Linton, 1969). Half of the Ss were given List 1 in training and List 2 in the test, while theother half of the Ss were given List 2 in training and List 1 in the test. One-third of the Ss were given a single training trial with the S-R1 pairs presented at a 4-sec rate; one-third of the Ss were given a single training trial with the S-R1 pairs presented at an 8-sec rate; one-third of the $\mathrm{Ss}$ were given the two training trials with the S-R1 pairs presented at a 4-sec rate. Each of the 12 sex-list-training groups was again Valley State College (SFVSC) Memory

Table 1

The 60 Stimulus Words and Their Normative Primaries $\left(R_{1}\right)$ at Three Levels of Free Associstion Strength

\begin{tabular}{lll}
\hline \multicolumn{1}{c}{ High FAS } & $\begin{array}{l}\text { FAS Level } \\
\text { Moderate FAS }\end{array}$ & Low FAS \\
\hline hammer-nail & candy-sweet & silk-satin \\
long-short & pain-hurt & fraud-fake \\
bark-dog & derby-hat & music-sound \\
spool-thread & bed-sleep & fancy-plain \\
globe-world & won-lost & made-make \\
poor-rich & dock-boat & jail-prison \\
freeze-cold & blue-red & bronze-gold \\
lily-flower & jelly-jam & church-steeple \\
boulder-rock & wagon-wheels & tie-bow \\
sister-brother & lion-tiger & engine-car \\
typhoid-fever & bake-cake & scene-picture \\
starved-hungry & tennis-ball & justice-peace \\
night-day & cork-bottle & sword-knife \\
give-take & income-tax & block-wood \\
bottom-top & fear-afraid & calm-quiet \\
atom-bomb & lad-boy & real-unreal \\
lock-key & fat-skinny & hole-ground \\
web-spider & chair-sit & mark-grade \\
blotter-ink & correct-wrong & quota-amount \\
major-minor & dad-father & thief-steal \\
\hline
\end{tabular}


rable 2

The Mean Proportion of $R_{1}$ s in the Test for Three Levels of 1 is for Si Training-Test Subgroups

\begin{tabular}{|c|c|c|c|c|c|c|c|}
\hline \multirow[b]{2}{*}{ AS } & \multicolumn{2}{|c|}{$4 \mathrm{Sec}$} & \multicolumn{2}{|c|}{$\begin{array}{l}\text { Training Level } \\
+ \text { Sec/ } 4 \text { Sec }\end{array}$} & \multicolumn{2}{|c|}{$8 \mathrm{Sic}$} & \multirow[b]{2}{*}{ Mein } \\
\hline & Test 4 & Test 8 & Test 4 & Test 8 & Tes1 4 & Test 8 & \\
\hline Strong & .94 & .96 & .96 & .99 & .98 & .99 & .97 \\
\hline Moderate & .82 & .89 & .92 & .96 & .92 & .95 & .91 \\
\hline Neak & .65 & .75 & .81 & .87 & .82 & .86 & .79 \\
\hline Mean & .80 & .87 & .90 & .94 & .91 & .93 & .89 \\
\hline
\end{tabular}

subdivided so that the stimulus words were presented during the test at a 4 -sec rate 10.24 Ss and at an 8 -sec rate to the otk:2r 24 Ss.

\section{RESULTS}

The number of errors (failures to give $\mathrm{R} 1$ prior to the appearance of the next stimulus word in the memory-drum window) in the test was analyzed with a 2 by 2 by 2 by 3 factorial analysis of variance with three repeated measures (strong FAS, mod FAS. and weak FAS). Although males made more errors than females ( $12.2 \%$ vs $9.0 \%$ ), neither this difference nor the difference between List 1 and List 2 was statistically reliable. Table 2 summarizes the mean probability of occurrence of $\mathrm{R} 1$ in the test for the three FAS levels for each of the six training-test subgroups.

The analysis of variance indicated that $S$ s were more likely to give $R 1$ in the test when they were given $8 \mathrm{sec}$ to respond than when they were given $4 \mathrm{sec} \quad[F(1,24)=5.17$. $p<.05]$. This difference in performance was primarily due to the fact that Ss rarely gave no response whatsoever during the response period when the stimuli were presented at an 8 -sec rate (2.3\%: omissions). However, when the stimuli were presented at a 4 -sec rate, there were more failures to respond ( $5.8 \%$ omissions).

The main effect of training level was statistically reliable $[\mathrm{F}(2,24)=8.24$, $\mathrm{p}<.05]$. The Duncan's Multiple Range Test (Edwards, 1960) indicated that the effect was due to the fact that Ss made significantly more errors in the test when given a single 4-sec training trial than when given either a single 8-sec training trial or two 4-sec training trials (alpha $=.05$, $\mathrm{df}=24$ ).

The probability of occurrence of R I was greatest for words from the strong-FAS group, medium for words from the mod.FAS group, and lowest for stimulus words from the weak-FAS group. The main effect of FAS level was statistically reliable $[F(2,48)=6.92, p<.05]$. The Duncan's Range Test that was used to compare the mean number of $\mathrm{R} 1 \mathrm{~s}$ to the stimulus words in the three FAS groups indicated that the difference between the high-FAS group and the mod.FAS group was not statistically reliable, al though all other differences were statistically significant (alpha $=.05$, $\mathrm{df}=48$ ).

The product-moment correlation between the frequency of occurrence of $R 1$ in the test and the frequency of occurrence of $\mathrm{R} 1$ in the drum norms was statistically significant $(r=.62, \mathrm{df}=58 . \mathrm{p}<.01)$. As in earlier research, more facilitation occurred for R $1 s$ with weak FAS than R 1 s with strong FAS. The magnitude of the product-moment correlation coefficient was undoubtedly attenuated by the pronounced ceiling effect and the consequent restricted range of the distribution of frequencies of $\mathrm{R}$ ls to the 60 words in the test.

The TLF was determined for the 20 words from the high.FAS group and the 20 words from the low-FAS group. The TLF of 9 of the 20 words in the low-FAS group was A or AA (high TLF), while the TLF of 15 of the 20 words in the low-FAS group was $A$ or AA. In order to determine if PAL can be predicted from FAS when the TLF of the stimulus words is high, the mean number of errors made in the test to the nine high-TLF/high-FAS words (1.7) was compared with the mean number of errors made in the test to the 15 high-TLF/low-FAS words (10.4). The difference was statistically reliable $[F(1,22)=13.28, \quad p<.05]$. Thus, PAL varied as a function of FAS with high-TLF words in the present experiment. The significance of the difference between the mean number of errors to the 11 words in the low-TLF/high-FAS group (1.4) and the mean number of errors to the five words in the low-TLF/low-FAS group (8.8) was not tested, both because of the small number of words in the low-TLF/low-FAS group and because it had already been well established that PAL can be predicted from FAS when the TLF of the stimulus words is low (Martin, 1964; Postman, 1962).

\section{DISCUSSION}

The present research confirmed the results of the studies discussed in an earlier report (Brotsky \& Linton, 1969). PAL varied as a function of FAS in each of the six training-test groups for high-TLF words as well as for low-TLF words. Morcover, the eflect of the WAT in earlier studies appears to have been negligible in producing the appropriate response set, since the percentage of R $1 \mathrm{~s}$ in the test for the eight Ss in Group 8:8 in the present study was within $1 \%$ of the percentage of RIs in the test for the $20 \mathrm{Ss}$ in an earlier study, where comparable training and test conditions were preceded by a WAT. Moreover, the present study replicated the failure to find differences in the performance of Ss who were given at least $8 \mathrm{sec}$ to study each S-R 1 pair, whether this $8 \mathrm{sec}$ was provided by a single training trial or by two 4-sec training trials. Since it appears that asymptotic PAL occurs with a single 8-sec training trial, or, perhaps, a single 6-sec training trial, faster exposure times, faster stimulus-presentation rates, larger word sets, or responses other than the normative primary may be necessary if a ceiling effect is to be avoided.

It appears that several additional steps must be taken in order to investigate the relationship between FAS and PAL. One research strategy would involve the independent manipulation of instructions and the subsequent assessment of Ss' verbal reports. This strategy would enable the theorist to determine if Ss' mediational rules or response sets must be designated as intervening variables, or if it is possible to adequately predict verbal learning on the basis of the antecedent conditions of the verbal-learning experiment.

\section{RIIERENCIS}

BROTSKY. S. J., LINTON, M. L. San l emando Valley State College menory drum norms. Technical Report No. 2, 1968. San I ernando Valley State College, Revearch Grant 4.259.01. SFVSC roundation.

BROTSKY. S. J., \& LINTON, M. L. Paired-associate icarning predicted from free-association strength. Psychonomic Science. $1969,16,6,305-307$.

EDWARDS. A. L. Experimental design in psychological research. New York: Rinehart, 1960.

MARTIN. J. G. Associative strength and word fricuency in paired-associate learning. Joumal of Verbal Learning \& Verbal Behavior. 1964, 3, 317-320.

POSTMAN, $L$. The effects of language habits on the acquisition and retention of verbal associations. Journal of rxperimental Psychology, 1962, 64, 7-19.

THORNDIKI:, I.. L., \& LORGF. I. The teachers wordbook of 30,000 words. New York: Teachers College. Columl 'a University, 1944. NOTI:

1. This research was supported, in part, by a Faculty Rexarch Award to the second author from the San Diego State College lioundation. 